\title{
Application of Calcium Chloride-Sodium Alginate to Improve the Texture of Quick-Frozen Heracleum moellendorffii
}

\author{
Xiao-mei Li, ${ }^{1}$ Li-kun Ren, ${ }^{1}$ Yang Yang, ${ }^{1}$ Xin Bian, ${ }^{1}$ Yu Fu, ${ }^{2}$ Lian-cheng Zhao, \\ Zhu-jing Xing, ${ }^{1}$ Yan-guo Shi, ${ }^{1}$ Wojciech Piekoszewski, ${ }^{3,4}$ and Na Zhang $\left({ }^{1}\right.$ \\ ${ }^{1}$ College of Food Engineering, Harbin University of Commerce, Harbin 150028, China \\ ${ }^{2}$ College of Food Science, Southwest University, No. 2 Tiansheng Road, Beibei District, Chongqing 400715, China \\ ${ }^{3}$ Department of Analytical Chemistry, Jagiellonian University, 30-386 Krakow, Poland \\ ${ }^{4}$ School of Biomedicine, Far Eastern Federal University, FEFU Campus, Vladivostok, Russia
}

Correspondence should be addressed to Na Zhang; foodzhangna@163.com

Received 7 January 2021; Revised 26 January 2021; Accepted 15 March 2021; Published 22 March 2021

Academic Editor: quancai sun

Copyright (C) 2021 Xiao-mei Li et al. This is an open access article distributed under the Creative Commons Attribution License, which permits unrestricted use, distribution, and reproduction in any medium, provided the original work is properly cited.

Heat-soak and quick freezing could deteriorate the texture of vegetables. In this work, it was found that calcium chloride-sodium alginate (SA) could improve the appearance, brittleness, and chewiness of processed Heracleum moellendorffii (HM), a kind of popular nutritious wild vegetable in China. The effect resulted from the increase of calcium content in the vegetable, which was closely related to the ratio of calcium chloride to SA, the concentration of texture retaining agent, and soaking time significantly $(P<0.01)$. The best way to maintain the texture was to soak HM in $4 \mathrm{~g} / \mathrm{L}$ of calcium chloride-SA (mass ratio $1: 2$ ) at $50^{\circ} \mathrm{C}$ for 30 minutes. The calcium content was increased to $71.56 \mathrm{mg} / 100 \mathrm{~g}$, and the brittleness and chewiness were $4630 \mathrm{gf}$ and $2583.33 \mathrm{gf}$, respectively. The microstructure found that calcium could adhere to an inherent position on the cell membrane and protected the sample from cell damage and chloroplast spilling from the cell during thawing and quick freezing. The results showed that calcium chloride-SA treatment may be a promising method to improve the texture of vegetables during quick-frozen storage.

\section{Introduction}

Heracleum moellendorffi is a perennial herbaceous herb of the Umbelliferae family. It is a particular hill potherb in Northeast China [1] with high levels of dietary fiber, amino acids, vitamins, and other nutrients [2]. Among them, the content of vitamin $\mathrm{C}$ is the most abundant and is more than ten times that of ordinary vegetables. Besides, some studies have confirmed that the species has high edible and medicinal value; for example, the blade can prevent high blood pressure, and the stem can improve heart disease and other diseases (rheumatism and headache) [3]. Thus, in recent years, HM has become more and more popular among the Chinese people because of its fine quality (e.g., verdant appearance, crispy taste, rich nutrition, and special aroma). Compared with other vegetables, it is usually regarded as a healthier foodstuff. HM is a wild vegetable that grows in forest districts, on river, lake shorelines, or hills [4]. It ripens in April and May and has a short period for the harvest, so it is necessary to take some strategies to preserve HM for the goal of year-round edible. Currently, the preservation techniques for seasonal vegetables are mainly based on quick-freezing preservation. However, there is a common problem with quick-freezing vegetables, which is the decreasing of brittleness and chewiness after thawing $[5,6]$. Therefore, with the increase of people's enthusiasm for nutrition and taste properties [7], keeping the freshness of $\mathrm{HM}$ in the frozen environment and keeping its texture after thawing are crucial to extending its market.

Some authors have reported that freezing changed the microstructure of plant tissues such as cell turgor, cells lost water, and shrinkage $[8,9]$, which may lead to the soft texture and the declined brittleness and chewiness thawing. The large ice crystals formed by traditional freezing will cause mechanical damage to the cell membrane, thereby causing the water loss of cells [10]. Compared to traditional 
freezing, quick freezing can form tiny ice crystals which shorten the time of maximum ice crystal generation, thereby reducing cell damage and water migration [11]. Moreover, the exogenous addition of a texture retaining agent can significantly relieve the cell damage caused by traditional freezing. The reason may be that the treatment of vegetables with a texture retaining agent before freezing can retain the inherent permeability of the vegetable cells to reduce cell damage. In the food industry, the exogenous calcium salt and exogenous pectin methylesterase (PME) were used as texture retaining agents together to catalyze the decomposition of pectin to form pectic acid [12]. Furthermore, pectic acid can react with $\mathrm{Ca}^{2+}$ to form calcium pectate, a molecular gel that can exist in the intercellular space, which retains the cell membrane in an inherent position after thawing, thereby enhancing the antiwrinkle behavior and antidestructive effect of cells [13]. Some studies also proved that calcium pectate has a great adhesion effect among the plant cell wall and cell membrane, which can prevent cell shrinkage and provide standby for tissues [14]. At present, apart from the addition of exogenous texture retaining agent, endogenous PME and $\mathrm{Ca}^{2+}$ have the same effect. The endogenously produced calcium pectate was safer and lower in cost than the exogenous PME, and the exogenous $\mathrm{Ca}^{2+}$ can activate endogenous PME more efficiently and produce calcium pectate more efficiently under heating conditions (Nipaporn et al., 2009). Therefore, the gel can retain the texture of the thawed vegetables to the maximum extent.

Nowadays, the commercially available frozen HM is processed by the traditional freezing method without texture protection [15], and the texture of HM is greatly reduced after thawing, which is greatly different from the sensory quality of fresh HM. On the contrary, the sensory quality of HM treated with texture retaining agents can retain to a large extent [9] (Chitra et al., 2010). However, little information is available about the influence of quick freezing and the protection effect of texture retaining agent on the texture of HM.

Therefore, the objective of this study was to evaluate the quality using microscopic (the increase of calcium and laser scanning confocal microscopy (LSCM)) and apparent measurements (crispiness and chewiness) to obtain the key pretreatment technology before the quick freezing of HM. This study can provide a theoretical basis for the texture protection of HM during quick freezing, and it has a practical guiding significance for the industrial production of the frozen storage of HM.

\section{Materials and Methods}

2.1. Materials and Chemicals. Fresh HM was provided by Dong-sheng Food Co., Ltd. (Beian, China), and selected according to the similar size for this study. Calcium lactate, calcium chloride, and sodium alginate (SA) were purchased from Yimeng Biotechnology Co., Ltd. (Zhejiang, China).

2.2. Screening of the Texture Retaining Agent. Calcium chloride, calcium lactate, and SA were chosen and compounded (the compound type texture retaining agent of calcium chloride-SA, calcium lactate-SA, and calcium chloride-calcium lactate) as texture retaining agents with 1 : $1(\mathrm{~g}: \mathrm{g})$. The calcium content increase of HM was used as an indicator to estimate the texture retaining agent to confirm the optimum texture retaining agents for the following experiments. The $\mathrm{HM}$ soaked in water without texture retaining agents at $50^{\circ} \mathrm{C}(n=3)$ was used as a negative control test. The HM was treated with the selected texture retaining agent. Then, the effects of compounding ratios of calcium chloride to SA, texture retaining agent concentrations, and soaking times on the calcium content increase, and the brittleness and chewiness of HM were investigated.

2.3. Determination of Calcium Components in HM. HM was soaked in the texture retaining agent (calcium chloride-SA) at $50^{\circ} \mathrm{C}$ for $30 \mathrm{~min}$. Next, $\mathrm{Ca}^{2+}$ was applied to stimulate the activity of PME [16] and further catalyze the formation of calcium pectate gel polymer that can be dissolved by $\mathrm{NaCl}$ solution. The unsoaked samples were used as a control group. Finally, the calcium content increase was conducted according to the atomic absorption spectrophotometry described by [17], with some modifications. The samples of the control group and the test group were homogenized, and a certain amount $( \pm 0.01 \mathrm{~g})$ of homogenate was weighed. Then, the dissolved calcium was extracted by $1 \mathrm{~mol} / \mathrm{L} \mathrm{NaCl}$ solution, volumed to a constant and filtered. The detailed parameters of the instrument were set as follows: slit: $0.5 \mathrm{~nm}$, gas flow: $1.8 \mathrm{~L} / \mathrm{min}$, flame type: air $-\mathrm{C}_{2} \mathrm{H}_{2}$, and wavelength: $422.7 \mathrm{~nm}$.

2.4. Determination of Brittleness and Chewiness. Texture properties of the HM stems soaked in calcium chloride-SA were assessed using a texture analyzer (New Plus Texture Analyzer, Isenso Intelligent Technology Co., Ltd., New York, USA), according to the method described by [18] with some modifications. The stems of the sample were processed into small cubic sections $\left(1.5 \times 1.5 \times 1.5 \mathrm{~cm}^{3}\right)$ and then penetrated using a Volodkevich-bite probe to represent brittleness. For chewiness analysis, a $\mathrm{P} / 0.5$ probe was used with $50 \%$ deformation and the parameters were set as follows: the pretest speed of $2.0 \mathrm{~mm} / \mathrm{s}$, test speed of $1.0 \mathrm{~mm} / \mathrm{s}$, the trigger force of $5.0 \mathrm{~g}$, and the time interval of $5 \mathrm{~s}$.

2.5. Observation of HM Cells. The stem and leaves of the HM were cut into small segments of $4-5 \mathrm{~cm}$ and cooled to room temperature $\left(25^{\circ} \mathrm{C}\right)$. Then, HM was soaked in the selected texture retaining solution (compound type compound mass ratio of $1: 1$ ) at $50^{\circ} \mathrm{C}$ for $10-15 \mathrm{~min}$. Then, the peroxidase of $\mathrm{HM}$ was inactivated at $90^{\circ} \mathrm{C}$ high-temperature bleaching for color retention and then cooled to room temperature $\left(25^{\circ} \mathrm{C}\right)$ with cold water. Finally, they were preserved at $-24^{\circ} \mathrm{C}$ for further experiments.

The samples were divided into 2 groups for the next step. The details were as follows: unfrozen group (fresh samples, samples soaked in water at $50^{\circ} \mathrm{C}$, and samples soaked in texture retaining agent at $50^{\circ} \mathrm{C}$ ) and frozen group (fresh samples + frozen, samples soaked in water at $50^{\circ} \mathrm{C}+$ frozen, 
and samples soaked in texture retaining agent at $50^{\circ} \mathrm{C}+$ frozen). A blade was used to cut a square with a side length of $1 \mathrm{~cm}$ on the stem and leaves of the HM and a pair of tweezers were used to remove the square skin. After that, the unfrozen samples and their thawed samples were subjected to the morphological observation of organelle chloroplast, separately. The fresh HM was used as a control. Chloroplasts were observed according to the method described by [19] with some modifications with the helium laser launcher of LSCM at $663 \mathrm{~nm}$ (TCS SP5, Leica Microsystems Co., Ltd., Frankfurt, Germany). The stems and leaves were examined at $75 \mu \mathrm{m}$ and $50 \mu \mathrm{m}$ magnification under incident light, respectively. Moreover, the temperature was set to $-24^{\circ} \mathrm{C}$ during the measurement.

2.6. Statistical Analysis. The correlation analysis of calcium content increase, brittleness, and chewiness in the experiment was assessed by SPSS 13.0 (SPSS Inc., Chicago, IL, USA) and then got the correlation coefficient. The data in the paper were expressed as means \pm standard deviation (SD) from at least three independent trials. Statistical significance of data was assessed by one-way ANOVA using SPSS 13.0. Significant differences $(P<0.05)$ between the average values were identified with the least significant difference procedure.

\section{Results and Discussion}

3.1. The Selection of Texture Retaining Agent. Texture properties are important in the assessment of consumer acceptability. The texture of HM refers to its sensory quality that includes brittleness and chewiness. Freezing is a major reason that causes texture change [20], such as softening phenomenon. Additionally, Agcam et al. reported that calcium salts can increase the PME activity of the samples, thus promoting the decomposition of pectin to react with $\mathrm{Ca}^{2}+$ to form calcium pectate gel, which can be enriched in the intercellular space [16], thereby reducing the deterioration of the sample texture. Therefore, in this paper, the level of the increase of calcium content was used as an indicator to explore the influence of texture retaining agents on the crispiness of HM. The results were shown in Table 1, the fresh sample did not detect the dissolved calcium, and the calcium content increase was regarded as zero.

Compared with No. 1, No. 2 and No. 3 had an increased content of calcium, but no significant difference was observed between the two groups $(P>0.05)$. In the experimental group, there is a significant difference in the calcium content increase of HM with different texture retaining agents $(P<0.05)$. No. 3 showed the most significant differences compared to the other groups $(P<0.01)$ and SA soaking had no impact on the calcium content increase. The calcium content increase in No. 4 was also lower. On the contrary, the calcium content increases significantly $(P<0.05)$ in No. 5, No. 6, and No. 7; however, there were no significant differences among the three groups $(P<0.05)$. The differences obtained among samples soaked in solutions with and without $\mathrm{Ca}^{2+}$ reflected the enhancing effect of $\mathrm{Ca}^{2+}$ on tissue structure. Moreover, the calcium content increase $(P<0.05)$ reached a maximum when the sample was soaked in calcium chloride-SA. This may be due to the synergistic effects of reagents [21]. Therefore, the texture retaining agent of calcium chloride-SA had the best effect on the texture of $\mathrm{HM}$ and was selected for further experiments.

\subsection{Effect of Texture Retaining Agent on the Calcium Content} Increase of HM. It can be seen from Figures 1 (a) 1(c) that the increase of calcium content in the HM depended on the change of the condition of the texture retaining agent. In the case of a fixed amount of calcium chloride, when the proportion of SA increased, the calcium content increase was significantly improved $(P<0.05)$ (Figure $1(\mathrm{a}))$. And the highest calcium content increase was observed when the ratio of calcium chloride to SA was $1: 2$. Furthermore, as shown in Figure 1(b), when the texture retaining agent concentration was $4 \mathrm{~g} / \mathrm{L}$, the calcium content increase of HM was significantly higher than other concentrations $(P<0.01)$. Moreover, the influence of soaking time on the calcium content increase of HM was firstly increased and then decreased (Figure 1(c)) and the calcium content increase was the highest with the soaking time of $30 \mathrm{~min}$.

These phenomena may be related to the following factors: firstly, SA has good gelation and viscosity property, and viscosity increases with the concentration of SA [22]. SA has a cross-linking effect with $\mathrm{Ca}^{2+}$, and then SA can cooperate with $\mathrm{Ca}^{2+}$ to enter the tissue of samples or adhere to the intercellular space, which had a synergistic effect on the texture. Secondly, the appropriate concentration of SA was beneficial for $\mathrm{Ca}^{2+}$ to contact with PME and activate the PME to form calcium pectate, which could attach to the intercellular space [23]. Calcium pectate had enhanced gelation [20], thereby supporting the cell wall and retaining the brittleness of the HM. Because of these factors, higher levels of calcium gains were achieved in this work as compared with previous literature results. Another research [24] showed that when blueberries were treated with calcium sulfate, the calcium content was less than it in this experiment.

Simultaneously, as shown in Figure 1(c), the calcium content increase of HM increased gradually with the increase of soaking time, until the calcium content decreased after soaking for $30 \mathrm{~min}$. The reason was that the stable temperature of $\mathrm{PME}$ is $35-50^{\circ} \mathrm{C}$, and the tolerance time is $40 \mathrm{~min}$. Soaking at $50^{\circ} \mathrm{C}$ for $30 \mathrm{~min}$, PME can achieve the proper activity, which is beneficial to exert the best catalytic effect [25]. However, prolonging soaking time at $50^{\circ} \mathrm{C}$ will result in a significant loss of active site due to changes in the structure of the enzyme protein, leading to a significant decrease in the activity of PME, which will lead to a significant decline in the amount of calcium pectate and a significant decrease in calcium content increase $(P<0.05)$.

\subsection{Effect of Texture Retaining Agent on the Texture of HM.} The calcium pectinate in the cells can reflect the effect of the texture retaining agent and brittleness and chewiness can indicate changes in texture. In the previous studies, 
TABLE 1: The effect of texture retaining agents on the calcium content increase.

\begin{tabular}{|c|c|c|c|}
\hline Group no. & Group & Dissolved content $(\mathrm{mg} / 100 \mathrm{~g})$ & Calcium content increase $(\mathrm{mg} / 100 \mathrm{~g})$ \\
\hline 1 & Fresh samples & Not detected & 0 \\
\hline 2 & Sample soaked in water & $23.71 \pm 3.40^{\mathrm{a}}$ & $2.01 \pm 0.62^{\mathrm{a}}$ \\
\hline 3 & SA & $26.09 \pm 4.12^{\mathrm{a}}$ & $2.38 \pm 0.49^{\mathrm{a}}$ \\
\hline 4 & Calcium lactate & $55.97 \pm 5.48^{\mathrm{b}}$ & $32.26 \pm 6.32^{\mathrm{b}}$ \\
\hline 5 & Calcium chloride & $71.69 \pm 7.86^{\mathrm{c}}$ & $47.98 \pm 8.17^{\mathrm{c}}$ \\
\hline 6 & Calcium lactate-SA & $74.91 \pm 6.65^{\mathrm{c}}$ & $51.20 \pm 5.94^{\mathrm{c}}$ \\
\hline 7 & Calcium lactate-calcium chloride & $75.10 \pm 10.13^{c}$ & $51.39 \pm 6.82^{\mathrm{c}}$ \\
\hline 8 & Calcium chloride-SA & $92.98 \pm 12.34^{\mathrm{d}}$ & $69.27 \pm 10.03^{\mathrm{d}}$ \\
\hline
\end{tabular}

Error bars indicate SD $(n=3)$. Different letters indicate significant differences $(P<0.05)$.

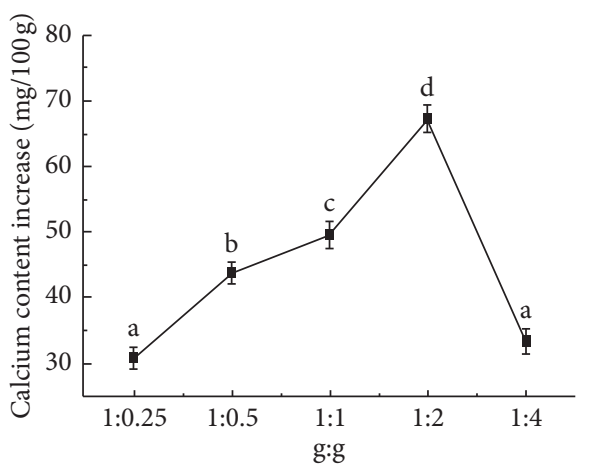

(a)

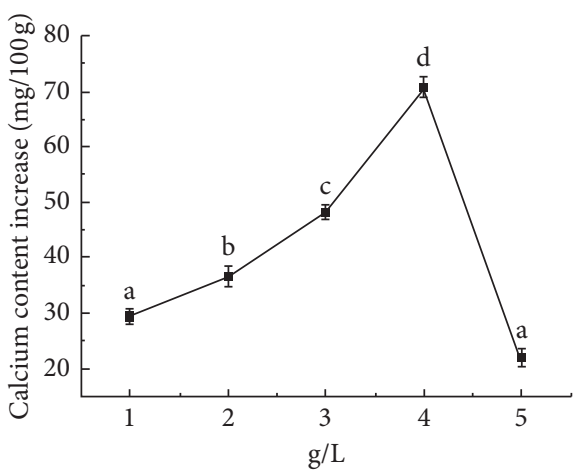

(b)

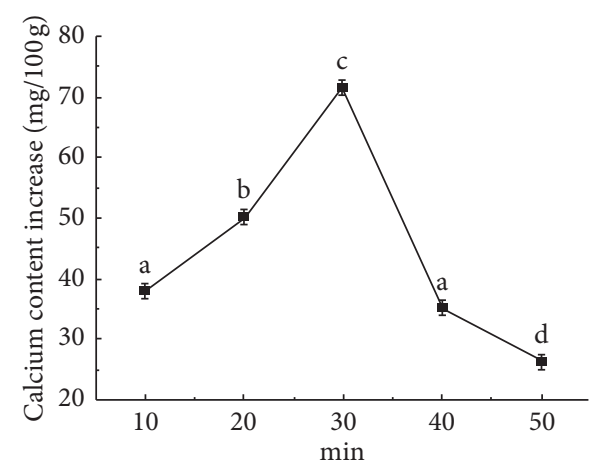

(c)

FIGURE 1: Effect of texture retaining agent (calcium chloride-sodium alginate (SA)) on calcium content increase of the Heracleum moellendorffii under different factors. (a) The effect of the ratio of calcium chloride to SA on the calcium content increase; (b) the effect of the concentration of the texture retaining agent on the calcium content increase; (c) the effect of the soaking time on the calcium content increase. Different letters within a line chart indicate significant differences $(P<0.05)$. Error bars indicate $\operatorname{SD}(n=3)$.

brittleness and chewiness were usually used as the main indicators to evaluate the texture of HM (Prabhakaran et al., 2006). Brittleness is the force required to make HM cut off by incisors and chewiness is used to describe the force required when HM was chewed until swallowed.

The results of the effect of calcium chloride-SA compounding ratio on the texture of HM were listed in Table 2A. The results suggested the appropriate compound ratio was 1 : 2; at this time, the brittleness and chewiness of HM were the closest to the parameters of the fresh sample. This result corroborates the results of Figure 1. Thus, a suitable compound ratio of texture retaining agents can effectively keep the brittleness and chewiness which can be very close to fresh samples.
Also, it can be found that the changes in brittleness and chewiness were closely correlated with the changes in the concentration of texture retaining agents (Table $2 \mathrm{~B}$ ). As the concentration increased, the brittleness and chewiness of HM significantly increased $(P<0.05)$. When the concentration was $4 \mathrm{~g} / \mathrm{L}$, the calcium content increase was maximized. In contrast with the present study, Rico et al. noticed that appropriate calcium ion concentration can improve the shelf life of carrot by improving the texture quality of the sample [12]. Similarly, Gonzalez found that, after calcium ion treatment, there was a reduced disassembly of the structure (molecular network structure formed by calcium pectate gel) and also an improvement in brittleness and chewiness [26]. 
TABLE 2: Effect of texture retaining agent on the texture of the Heracleum moellendorffii under different factors.

\begin{tabular}{cccc}
\hline Factor & Experimental group & Brittleness (gf) & Chewiness (gf) \\
\hline & $1: 025$ & $2038 \pm 84.31^{\mathrm{a}}$ & $1418.31 \pm 50.89^{\mathrm{a}}$ \\
$\mathrm{A}$ & $1: 0.5$ & $2521 \pm 79.25^{\mathrm{b}}$ & $1670.28 \pm 57.65^{\mathrm{a}, \mathrm{b}}$ \\
& $1: 1$ & $3044 \pm 91.26^{\mathrm{c}}$ & $1902.31 \pm 55.21^{\mathrm{b}, \mathrm{d}}$ \\
& $1: 2$ & $3810 \pm 92.35^{\mathrm{d}}$ & $2064.33 \pm 67.19^{\mathrm{c}, \mathrm{d}}$ \\
& $1: 4$ & $1077 \pm 53.57^{\mathrm{e}}$ & $672.18 \pm 34.11^{\mathrm{e}}$ \\
\hline & $1 \mathrm{~g} / \mathrm{L}$ & $1908 \pm 67.32^{\mathrm{a}}$ & $927.61 \pm 52.33^{\mathrm{a}}$ \\
$\mathrm{B}$ & $2 \mathrm{~g} / \mathrm{L}$ & $2612 \pm 73.89^{\mathrm{b}}$ & $1920.55 \pm 70.13^{\mathrm{b}}$ \\
& $3 \mathrm{~g} / \mathrm{L}$ & $3726 \pm 88.13^{\mathrm{c}}$ & $2187.92 \pm 75.24^{\mathrm{c}}$ \\
& $4 \mathrm{~g} / \mathrm{L}$ & $4630 \pm 87.26^{\mathrm{d}}$ & $2538.33 \pm 81.60^{\mathrm{d}}$ \\
& $5 \mathrm{~g} / \mathrm{L}$ & $1911 \pm 70.12^{\mathrm{a}}$ & $1101.65 \pm 57.12^{\mathrm{e}}$ \\
\hline & $10 \mathrm{~min}$ & $3067 \pm 40.56^{\mathrm{a}}$ & $1556.36 \pm 40.56^{\mathrm{a}}$ \\
$\mathrm{C}$ & $20 \mathrm{~min}$ & $3289 \pm 58.22^{\mathrm{b}}$ & $1990.22 \pm 52.24^{\mathrm{b}}$ \\
& $30 \mathrm{~min}$ & $3890 \pm 61.28^{\mathrm{c}}$ & $2278.15 \pm 49.13^{\mathrm{c}}$ \\
& $40 \mathrm{~min}$ & $3301 \pm 52.36^{\mathrm{d}, \mathrm{b}}$ & $1817.64 \pm 42.32^{\mathrm{b}}$ \\
& $50 \mathrm{~min}$ & $2917 \pm 48.27^{\mathrm{a}}$ & $1393.56 \pm 48.69^{\mathrm{a}}$ \\
\hline
\end{tabular}

${ }^{a}$ The texture retaining agent concentration factor experiment; ${ }^{b}$ the proportional factor experiment of the texture retaining agent calcium chloridesodium alginate; ${ }^{\mathrm{c}}$ the soaking time factor experiment. Error bars indicate SD $(n=3)$. Different letters indicate significant differences $(P<0.05)$.

An increase in soaking time improved the brittleness and chewiness of HM gradually until it reached $30 \mathrm{~min}$. Sensory quality results after thawing were effective $(P<0.01)$. There was a positive correlation between soaking time and the activity of pectin methylesterase (PME). The higher the activity of PME, the more the calcium pectate gel formed in cells [27]. The presence of calcium pectate gel increased mechanical properties such as brittleness and chewiness due to the close connection between cells [28].

\subsection{Analysis of the Correlation between Calcium Content,} Brittleness, and Chewiness. The increase of calcium was used to express the chemical changes of HM and the texture of HM was represented by brittleness and chewiness, which together reflect the effect of texture retaining agent on HM. Thus, in this report, the correlation of calcium content, brittleness, and chewiness in the process of texture retaining of HM was investigated. As shown in Table 3, the correlation coefficient between calcium content, brittleness, and chewiness was 0.792 , which was a significantly positive correlation $(P<0.01)$. The correlation coefficient between brittleness and chewiness was 0.930 , which was a significantly positive correlation $(P<0.05)$. It can be explained that, in the process of texture retaining of $\mathrm{HM}$, the change of calcium content was directly related to the brittleness and chewiness, and it also proved that the calcium content increase can enhance the brittleness and chewiness of HM. These effects showed that it is reasonable and feasible to select the change of calcium content, the crispness, and the chewiness index to evaluate the effect of the soaking of the HM before quick freezing on the crispness and chewiness after thawing. Further from both microscopic and apparent aspects, it reveals the mechanism and chemical essence of the texture retaining agent.
3.5. Microstructural Changes of HM under the Action of Texture Retaining Agent. Freezing can damage the organelles of stems and leaves of green plants, among which, chloroplast is a kind of organelle that is extremely sensitive to low temperature. In a low-temperature environment, the chloroplasts swell, causing disordered chloroplasts sorting and adhesion [29]. At the same time, the water in the cells forms ice crystals, which has a destructive effect on the cell membrane wall. After thawing, the cells lose water and shrink, which magnifies the problem of chloroplast sorting disorder and adhesion. The calcium pectate molecular gel adheres to the cell gap and supports the cell membrane wall, which can resist the mechanical damage of cells. Therefore, the microscopic observation method was used to observe and evaluate the changes in cell morphology before and after freezing treatment in Figures 2-5.

The changes in the position and state of chloroplasts in the cell walls and cell membrane of leaves epidermal cells [29] of HM were observed. Figures 2(a), 2(c), and 3(b) were not frozen and the untreated sample (Figure 2(a)) was a control group. The chloroplasts of each group were dispersed to the inner wall of the cells to varying degrees and were regularly granular. In contrast, the chloroplast morphology of frozen groups (Figures 2(b), 3(a), and 3(c)) changed to varying degrees, indicating that the freezing caused damage against the cells. Among them, Figure 3(a) only changed the chloroplasts of the cells with water soaking at $50^{\circ} \mathrm{C}$, and the chloroplasts overflowed from the cells and adhered to the chloroplasts of other cells to form a network structure [30]. It indicated that the cell membrane and organelles were damaged by freezing after soaking in the water at $50^{\circ} \mathrm{C}$ [31]. Secondly, the chloroplasts of the cells aggregated in the fresh sample after freezing (Figure 2(b)) but no overflow occurred. In Figure 3(c), after 30 minutes of treatment by a $50^{\circ} \mathrm{C}$ texture retaining agent, the chloroplasts of cells were the smallest. Although there was some aggregation, the cell membrane structure was not destroyed and still observed to be granular. This result indicated that the addition of the texture retaining agent under the same condition can prevent the damage of the cell membrane and organelle caused by freezing, thereby affecting the texture of $\mathrm{HM}$ in nature.

In Figures 4 and 5, the changes in the position and state of chloroplasts in the cell walls and cell membrane of stems epidermal cells of HM could be observed by LSCM. Figures 4(b), 5(a), and 5(c) were frozen groups, and their chloroplasts had significantly more changes in the adhesion than the unfrozen group. In Figure 4(a), the chloroplasts were evenly dispersed in the inner wall of the cells and were regular particles. In contrast, although the chloroplasts in Figures 4(c) and 5(b) were dispersed in the inner wall in the form of particles, the degree of dispersion was not uniform. This was due to the strong peroxidase activity at $50^{\circ} \mathrm{C}$, which caused an enzymatic reaction of chlorophyll in the cell $[9,32]$, resulting in a change in the degree of chloroplast dispersion. Among them, Figures 4(a), 4(c), and 5(b) were unfrozen groups, and the chloroplasts of the cells were dispersed in the cells with a 
TABLE 3: Correlation analysis between calcium content increase, brittleness, and chewiness.

\begin{tabular}{|c|c|c|c|}
\hline Index & Calcium content increase $(\mathrm{mg} / 100 \mathrm{~g})$ & Brittleness (gf) & Chewiness (gf) \\
\hline Calcium content increase $(\mathrm{mg} / 100 \mathrm{~g})$ & 1 & $0.792^{* *}$ & $0.792^{* *}$ \\
\hline Brittleness (gf) & $0.792^{* *}$ & 1 & $0.930^{* *}$ \\
\hline Chewiness (gf) & $0.792^{* *}$ & $0.930^{* *}$ & 1 \\
\hline
\end{tabular}

${ }^{* *} 0.01$ level (two-tailed), significant correlation.
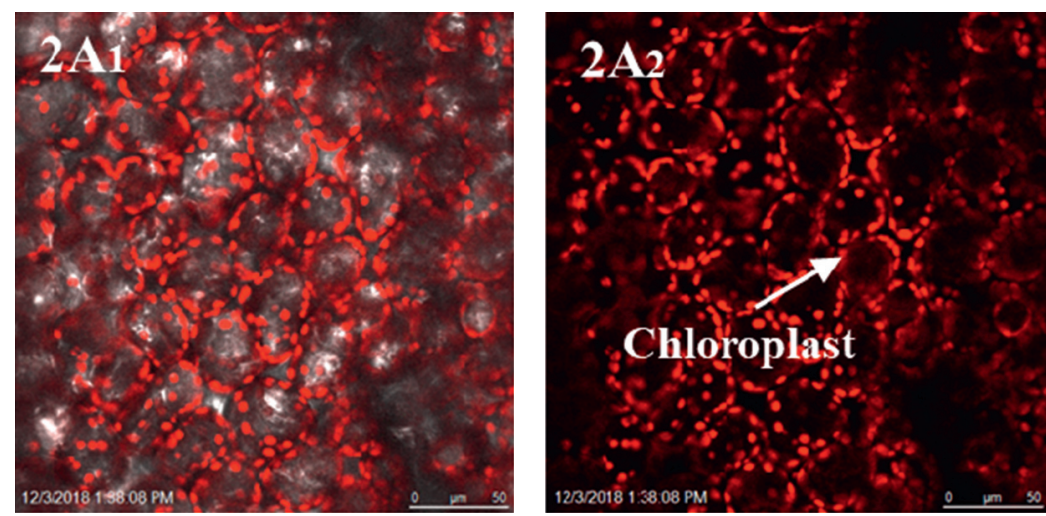

(a)
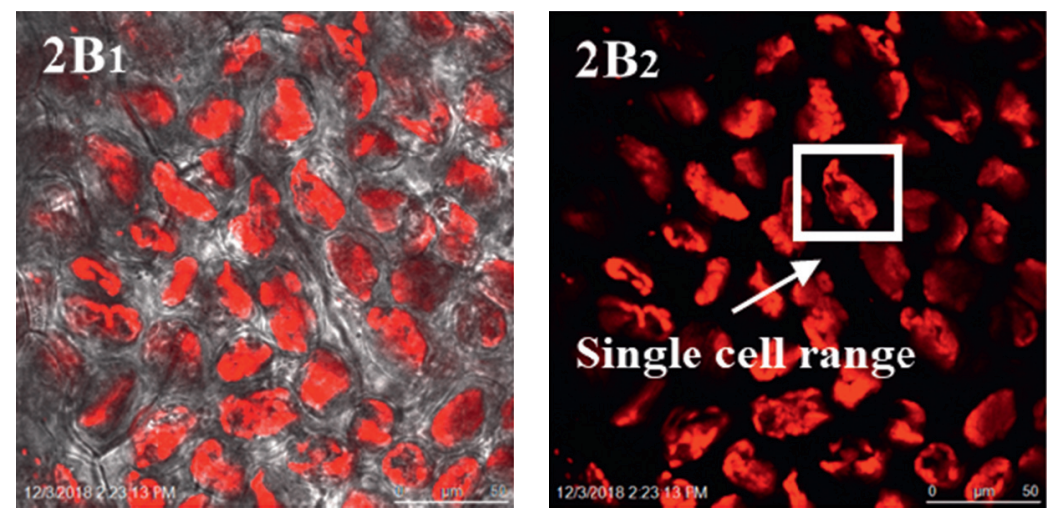

(b)
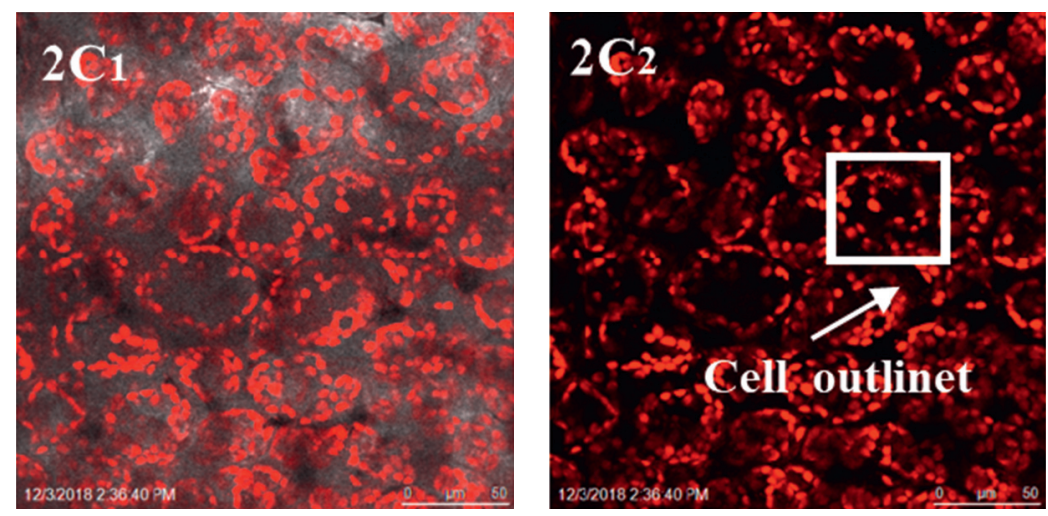

(c)
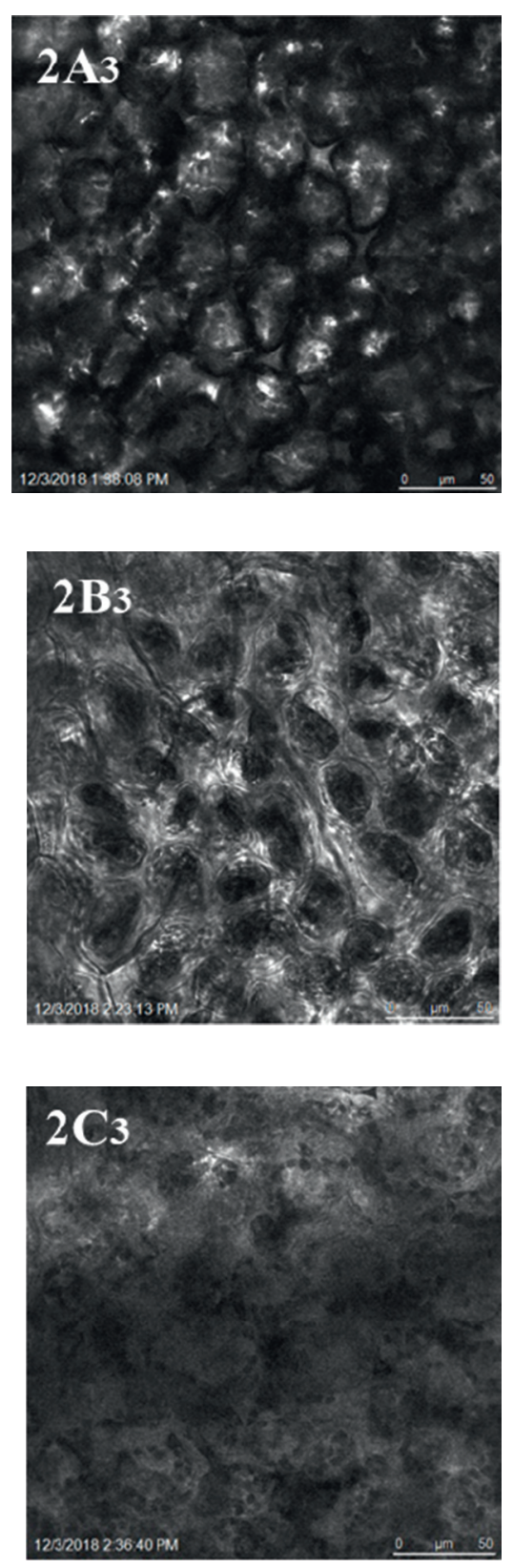

Figure 2: Microscopic observation of leaves epidermal cells of Heracleum moellendorffii. (a) A fresh sample; (b) a fresh sample after thawed; (c) a sample soaked in water at $50^{\circ} \mathrm{C}$. The "index 1 " represents the fluorescence and bright field superposition; the "index 2 " represents the fluorescence; the "index 3 " represents the bright field. 

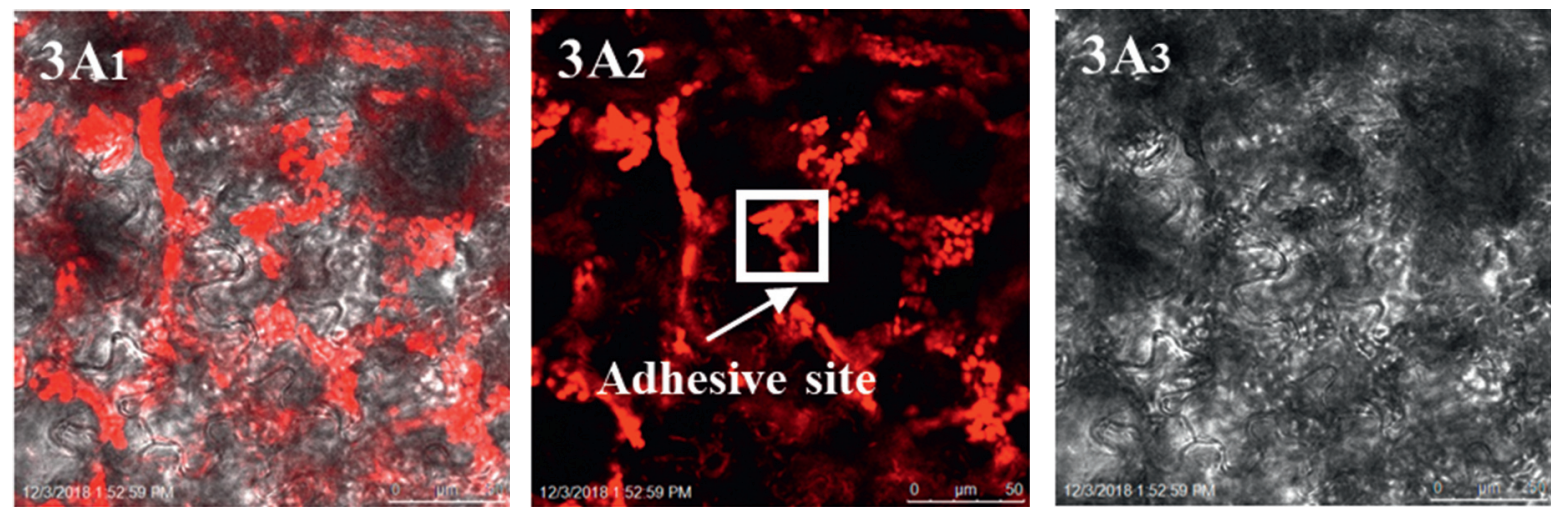

(a)
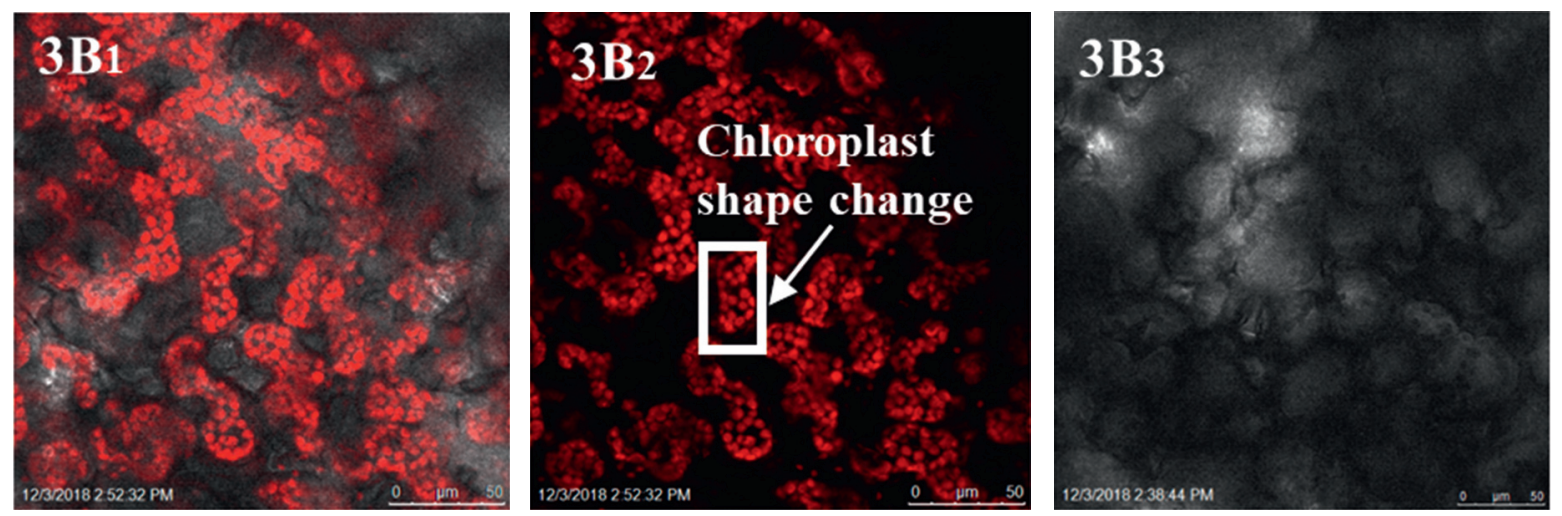

(b)
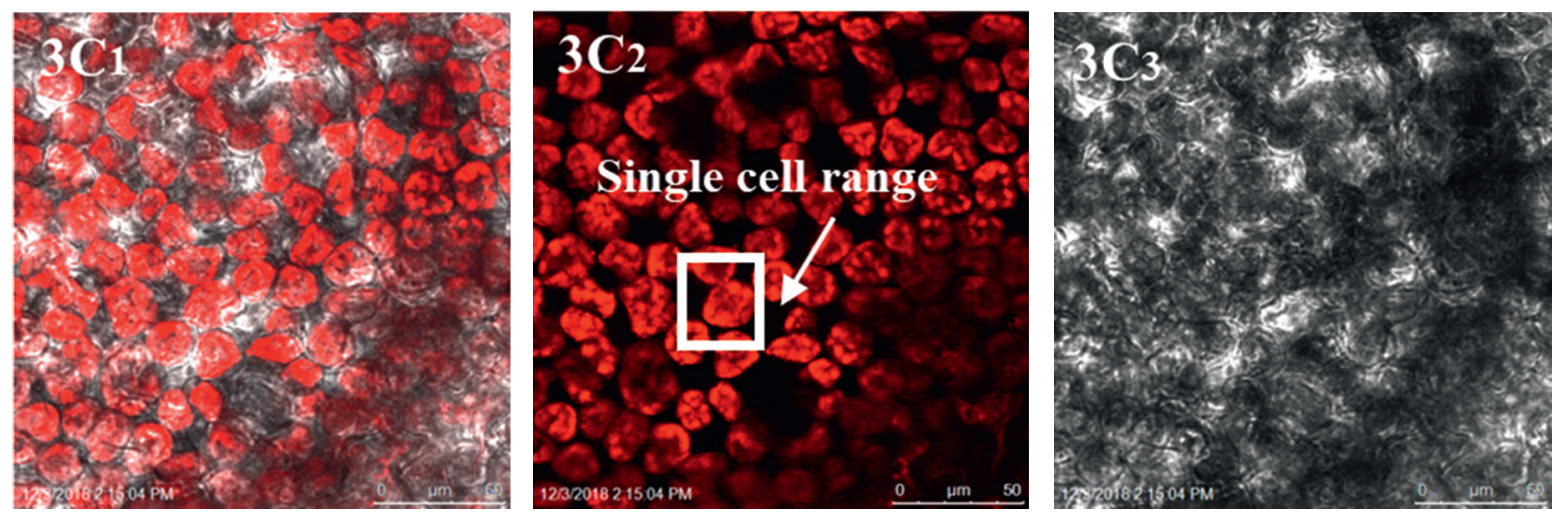

(c)

Figure 3: Microscopic observation of leaves epidermal cells of Heracleum moellendorffii. (a) A soaked sample in water after thawed; (b) a sample soaked with a texture retaining agent at $50^{\circ} \mathrm{C}$; (c) a sample soaked with a texture retaining agent at $50^{\circ} \mathrm{C}$ after thawed. The "index 1 " represents the fluorescence and bright field superposition; the "index 2 " represents the fluorescence; the "index 3 " represents the bright field.

granular shape. Among them, chloroplasts gathered but did not overflow, chloroplasts in Figure 5(a) overflowed from the cells and adhered to the chloroplasts of other cells to form a network structure, it showed that the cell membrane and cell wall were broken, the chloroplast in Figure 5(c) was the smallest, although there was a certain gather, the cell membrane structure was not destroyed, and the granular of chloroplasts could be observed. It meant that samples soaked by texture retaining agent before quick freezing could make the ice crystals in the cell fluid form quickly and small, which could prevent the cell membrane from damage. As can be seen from Figure 5(a), soaking in $50^{\circ} \mathrm{C}$ water caused the cell wall to rupture, which was more serious. This may be caused by a part of the chloroplasts overflowing into the water during the warm water treatment, and the texture retaining agent formed a gel network structure inside the texture to protect the chloroplast from overflowing [32]. Adding the texture retaining agent during soaking under the same conditions can reduce the rupture and damage of the cell 

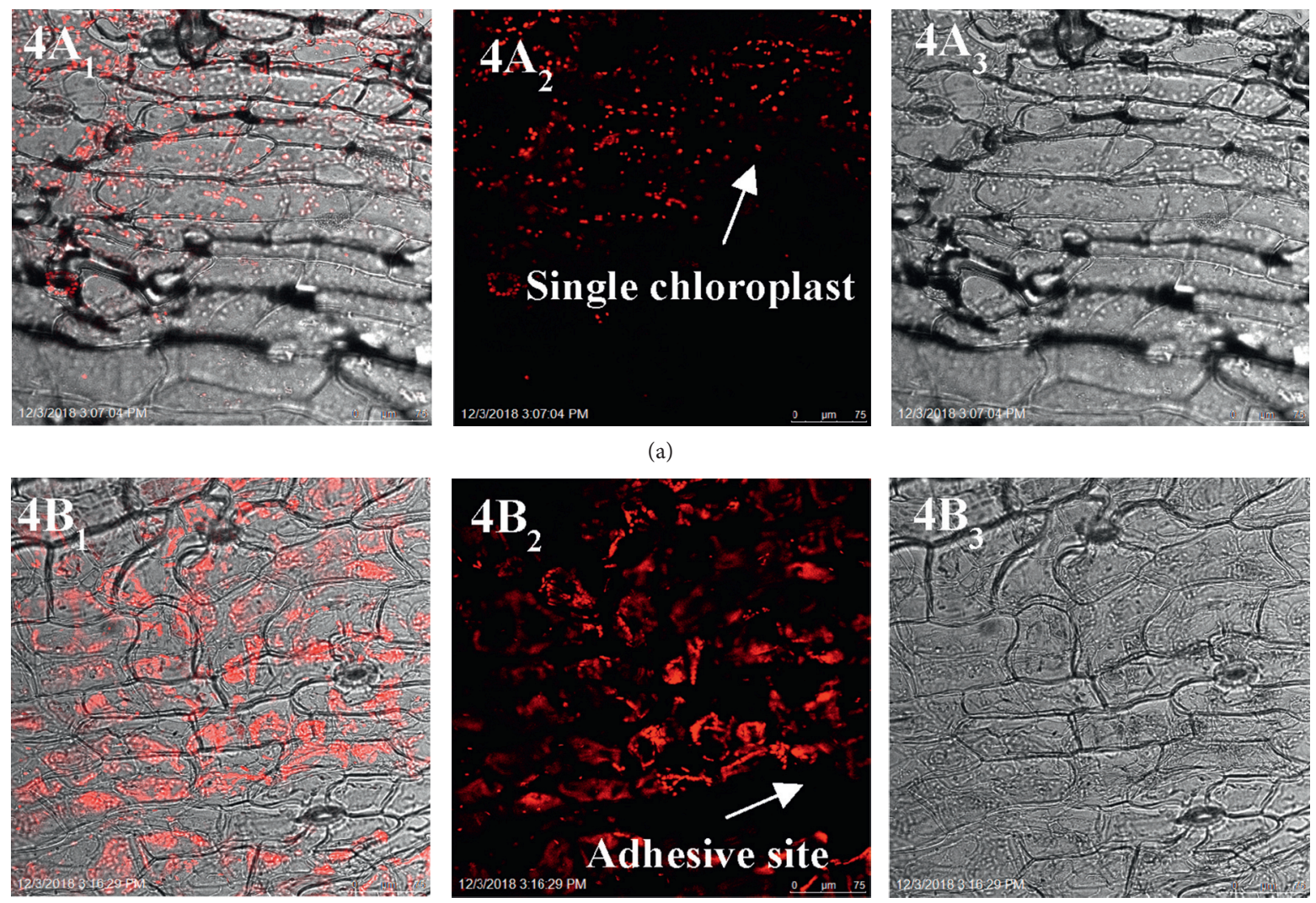

(b)
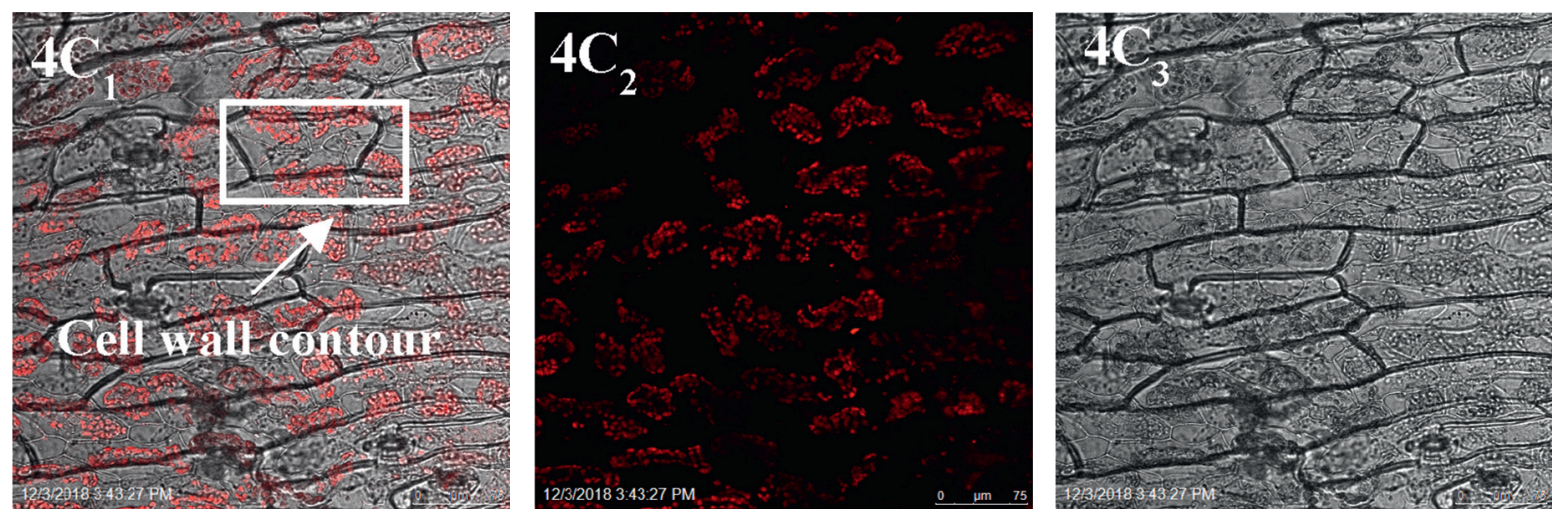

(c)

FIGURE 4: Microscopic observation of stems epidermal cells of Heracleum moellendorffii. (a) A fresh sample; (b) a fresh sample after thawed; (c) a sample soaked in water at $50^{\circ} \mathrm{C}$; (d) a soaked sample in water after thawed; (e) a sample soaked with a texture retaining agent at $50^{\circ} \mathrm{C}$; (f) a sample soaked with a texture retaining agent at $50^{\circ} \mathrm{C}$. The "index 1" represents the fluorescence and bright field superposition; the "index 2 " represents the fluorescence; the "index 3 " represents the bright field.

membrane and cell wall caused by freezing. It showed that the compound SA-calcium chloride that formed calcium pectinate in the cells could enhance the support function of the cell wall and the ability to resist mechanical damage, thereby maintaining the brittleness and chewiness of HM to a certain extent in essence, and then had a significant positive effect on the texture of hill potherbs and the appearance of commodities.
In summary, changes in the position and adhesion between chloroplasts were microscopically observed in Figures 2 to 5. These results suggested the texture retaining agent had a synergistic effect on enhancing the brittleness and chewiness of HM. The microscopic gel material in the texture retaining agent was the key to enhancing the sensory quality. According to the experiments, it is the main reason to enhance sensory quality with the increased calcium content. 

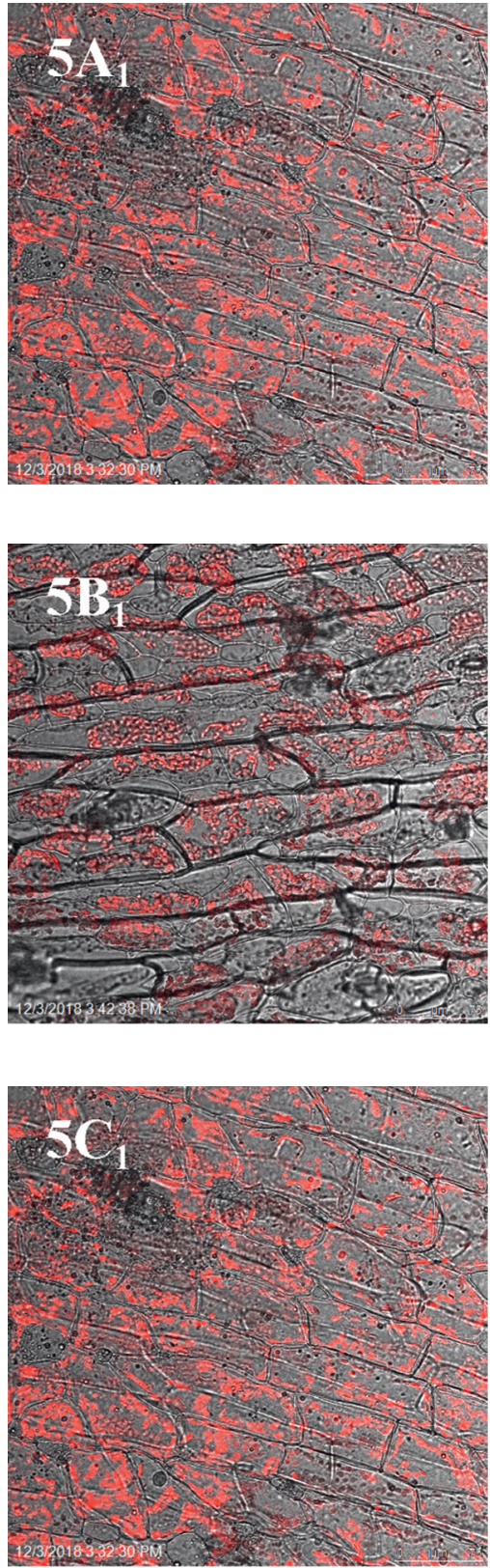

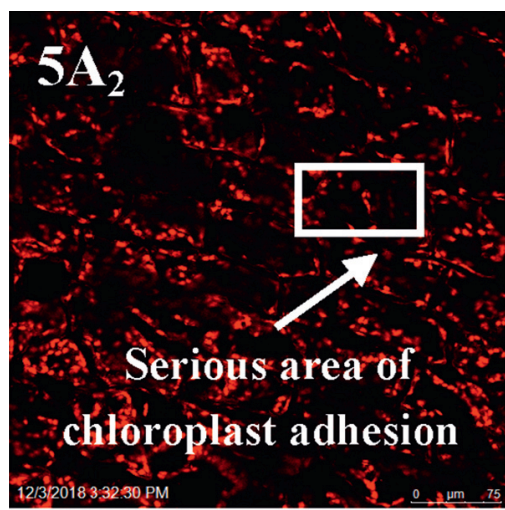

(a)

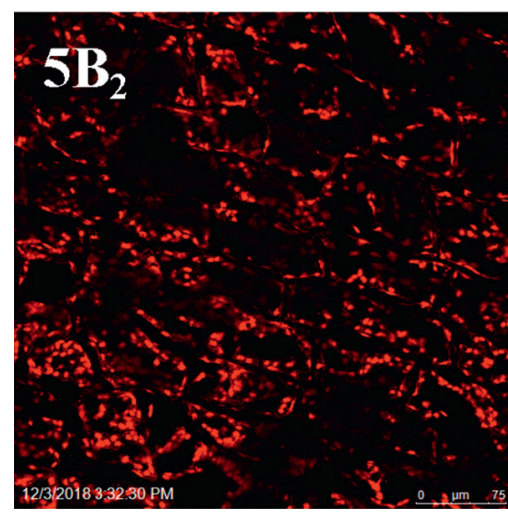

(b)

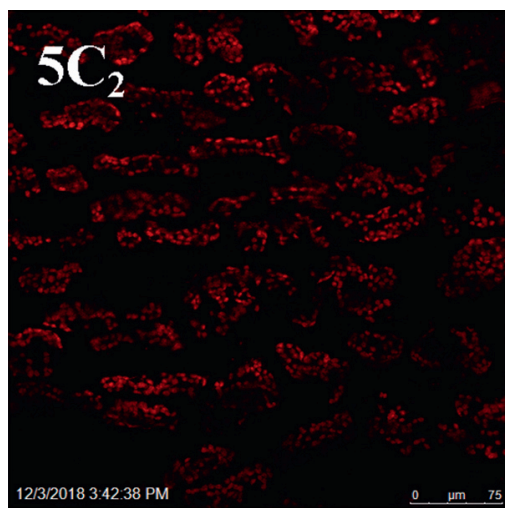

(c)
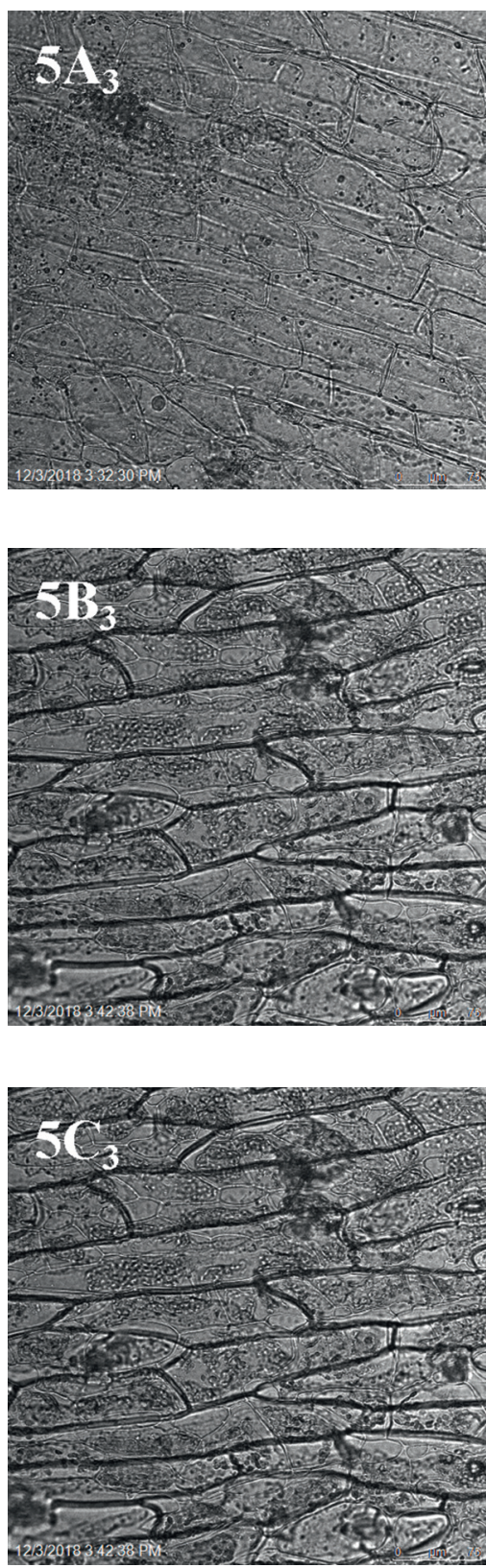

Figure 5: Microscopic observation of stems epidermal cells of Heracleum moellendorffii. (a) A soaked sample in water after thawed; (b) a sample soaked with a texture retaining agent at $50^{\circ} \mathrm{C}$; (c) a sample soaked with a texture retaining agent at $50^{\circ} \mathrm{C}$ after thawed. The "index 1 " represents the fluorescence and bright field superposition; the "index 2 " represents the fluorescence; the "index 3 " represents the bright field.

\section{Conclusions}

In this work, we selected a texture retaining agent and then determined its optimum treatment for HM, and the change of microstructure and sensory quality was analyzed. The calcium content increase was $71.56 \mathrm{mg}$ in the $100 \mathrm{~g}$ sample when the vegetable was soaking at $50^{\circ} \mathrm{C}$ for 30 minutes with a ratio of calcium chloride to $\mathrm{SA}(1: 2)$. Correlation analysis showed that the microscopic calcium content increase was positively correlated with the brittleness and chewiness (correlation coefficient 0.792). Furthermore, the chloroplast morphology of the frozen group treated with texture retaining agent was well maintained. Most of the chloroplasts were in granular dispersion state, without overflow, with relatively small cell damage, suggesting that the texture (brittleness and mastication) was the closest to the fresh sample. The results confirmed that calcium chloride-SA can be used as a texture retaining agent during the quick- 
freezing storage of $\mathrm{HM}$, thereby providing an effective way to inhibit the texture change caused by frozen storage.

\section{Data Availability}

The authors confirm that the data supporting the findings of this study are available within the article.

\section{Conflicts of Interest}

The authors declare that they have no conflicts of interest.

\section{Authors' Contributions}

Xiao-mei Li and Yang Yang contributed equally to this work.

\section{Acknowledgments}

This work was financially supported by the National Natural Science Foundation (Grant nos. 32072258 and 31871747), the Major Science and Technology Program of Heilongjiang (Grant nos. 2019ZX08B02 and 2020ZX08B02), the Harbin University of Commerce "Young Innovative Talents" Support Program (Grant nos. 2019CX06 and 2020CX26), and the Central Financial Support for the Development of Local Colleges and Universities.

\section{References}

[1] M. Alam, B.-J. Seo, P. Zhao, and S.-H. Lee, “Anti-melanogenic activities of heracleum moellendorffii via ERK1/2-mediated MITF downregulation," International Journal of Molecular Sciences, vol. 17, no. 11, pp. 1844-1858, 2016.

[2] S. Liu, X. Jiang, Z. Liu, Y. Cheng, T. Sun, and X. Yu, "Mechanism of the breaking of seed dormancy by flower thinning in heracleum moellendorffii hance," Journal of Plant Growth Regulation, vol. 38, no. 3, pp. 870-882, 2019.

[3] S. Q. Diao, N. N. Zhu, and G. R. Sun, "Nutrients and processing characteristics of Spuriopimpinella brachycarpa (in Chinese)," Journal of Northeast Forestry University, vol. 38, pp. 48-50, 2010.

[4] H. Zhang, Y. Su, X. Wang et al., "Antidiabetic activity and chemical constituents of the aerial parts of Heracleum dissectum Ledeb," Food Chemistry, vol. 214, pp. 572-579, 2017.

[5] Y. Gao, Y. Liu, Z.-G. Wang, and H.-1. Zhang, "Chemical constituents of Heracleum dissectum and their cytotoxic activity," Phytochemistry Letters, vol. 10, pp. 276-280, 2014.

[6] M. Paciulli, T. Ganino, N. Pellegrini et al., "Impact of the industrial freezing process on selected vegetables - Part I. Structure, texture and antioxidant capacity," Food Research International, vol. 74, pp. 329-337, 2015.

[7] A. C. Dussault and E. Desaylniers, "Natural food," Encyclopedia of Food and Agricultural Ethics, vol. 80, no. September, pp. 1-11, 2013.

[8] T. Arunyanart, U. Siripatrawan, Y. Makino, and S. Oshita, "A new approach for the preservation of apple tissue by using a combined method of xenon hydrate formation and freezing," Innovative Food Science \& Emerging Technologies, vol. 26, pp. 278-285, 2014.

[9] D. Li, Z. Zhu, and D.-W. Sun, "Effects of freezing on cell structure of fresh cellular food materials: a review," Trends in Food Science \& Technology, vol. 75, pp. 46-55, 2018.
[10] D. J. Cosgrove, "Loosening of plant cell walls by expansins," Nature, vol. 407, no. 6802, pp. 321-326, 2000.

[11] Y. Karakurt and D. J. Huber, "Activities of several membrane and cell-wall hydrolases, ethylene biosynthetic enzymes, and cell wall polyuronide degradation during low-temperature storage of intact and fresh-cut papaya (Carica papaya) fruit," Postharvest Biology and Technology, vol. 28, no. 2, pp. 219229, 2003.

[12] D. Rico, A. B. Martín-Diana, J. M. Frías, J. M. Barat, G. T. M. Henehan, and C. Barry-Ryan, "Improvement in texture using calcium lactate and heat-shock treatments for stored ready-to-eat carrots," Journal of Food Engineering, vol. 79, no. 4, pp. 1196-1206, 2007.

[13] A. Ortiz, J. Graell, and I. Lara, "Preharvest calcium applications inhibit some cell wall-modifying enzyme activities and delay cell wall disassembly at commercial harvest of 'Fuji Kiku-8' apples," Postharvest Biology and Technology, vol. 62, no. 2, pp. 161-167, 2011.

[14] O. Yuliarti, S. Y. Chong, and K. K. T. Goh, "Physicochemical properties of pectin from green jelly leaf (Cyclea barbata Miers)," International Journal of Biological Macromolecules, vol. 103, pp. 1146-1154, 2017.

[15] G. Petzold, M. Caro, and J. Moreno, "Influence of blanching, freezing and frozen storage on physicochemical properties of broad beans (Vicia faba L)," International Journal of Refrigeration, vol. 40, pp. 429-434, 2014.

[16] E. Agcam, A. Akyıldız, and G. A. Evrendilek, "Effects of PEF and heat pasteurization on PME activity in orange juice with regard to a new inactivation kinetic model," Food Chemistry, vol. 165, pp. 70-76, 2014.

[17] D. B. Kiin-Kabari, S. Y. Giami, and B. Ndokiari, "Bioavailability of Mineral Nutrients in Plantain Based Product Enriched With Bambara Groundnut Protein Concentrate," Journal of Food Research, vol. 4, no. 4, pp. 74-80, 2015.

[18] M. S. Alamri, S. Hussain, A. Mohamed, and M. A. Osman, "Wheat flour solvent retention capacity, pasting and gel texture," Quality Assurance and Safety of Crops and Foods, vol. 8, no. 3, pp. 439-445, 2016.

[19] G. N. Chen, Z. F. Huang, R. Chen, J. Q. Lin, and L. J. Wang, "Fluorescence spectra and imaging of platymonas subcordiformis via LSCM (in Chinese)," Spectroscopy and Spectral Analysis, vol. 29, pp. 2330-2333, 2009.

[20] X. Guo, H. Duan, C. Wang, and X. Huang, "Characteristics of Two Calcium Pectinates Prepared from Citrus Pectin Using Either Calcium Chloride or Calcium Hydroxide," Journal of Agricultural and Food Chemistry, vol. 62, no. 27, pp. 63546361, 2014.

[21] Y. Wu, G. Zhao, C. Wei, S. Liu, Y. Fu, and X. Liu, "Effect of calcium chloride concentration on output force in electrical actuator made of sodium alginate gel," IOP Conference Series: Materials Science and Engineering, vol. 284, Article ID 012022, 2018.

[22] J. Ma, Y. Lin, X. Chen, B. Zhao, and J. Zhang, "Flow behavior, thixotropy and dynamical viscoelasticity of sodium alginate aqueous solutions," Food Hydrocolloids, vol. 38, pp. 119-128, 2014.

[23] T. E. Proseus and J. S. Boyer, "Calcium deprivation disrupts enlargement of Chara corallina cells: further evidence for the calcium pectate cycle," Journal of Experimental Botany, vol. 63, no. 10, pp. 3953-3958, 2012.

[24] P. Angeletti, H. Castagnasso, E. Miceli et al., "Effect of preharvest calcium applications on postharvest quality, softening and cell wall degradation of two blueberry (Vaccinium 
corymbosum) varieties," Postharvest Biology and Technology, vol. 58, no. 2, pp. 98-103, 2010.

[25] R. Koshani, E. Ziaee, M. Niakousari, and M.-T. Golmakani, "Optimization of Thermal and Thermosonication Treatments on Pectin Methyl Esterase Inactivation of Sour Orange Juice (C itrus aurantium)," Journal of Food Processing and Preservation, vol. 39, no. 6, pp. 567-573, 2015.

[26] M. E. Gonzalez, J. A. Jernstedt, D. C. Slaughter, and D. M. Barrett, "Microscopic quantification of cell integrity in raw and processed onion parenchyma cells," Journal of Food Science, vol. 75, no. 7, pp. E402-E408, 2010.

[27] L. F. Goulao, J. Santos, I. de Sousa, and C. M. Oliveira, "Patterns of enzymatic activity of cell wall-modifying enzymes during growth and ripening of apples," Postharvest Biology and Technology, vol. 43, no. 3, pp. 307-318, 2007.

[28] D. Cantu, A. R. Vicente, J. M. Labavitch, A. B. Bennett, and A. L. T. Powell, "Strangers in the matrix: plant cell walls and pathogen susceptibility," Trends in Plant Science, vol. 13, no. 11, pp. 610-617, 2008.

[29] K. A. Fayez, D. E. M. Radwan, A. K. Mohamed, and A. M. Abdelrahman, "Fusilade herbicide causes alterations in chloroplast ultrastructure, pigment content and physiological activities of peanut leaves," Photosynthetica, vol. 52, no. 4, pp. 548-554, 2014.

[30] L. D. Bartolo, "Cell adhesion M//encyclopedia of membranes," 2014.

[31] T. Itakura, T. Suzuki, M. Watanabe, and H. Ando, "The influence of damage of cell membrane on softening of strawberry tissue due to freeze-thawing," Acta Horticulturae, vol. 1049, no. 1049, pp. 771-776, 2014.

[32] M. C. Beckerle, K. Burridge, G. N. Demartino, and D. E. Croall, "Colocalization of calcium-dependent protease II and one of its substrates at sites of cell adhesion," Cell, vol. 51, no. 4, pp. 569-577, 1987. 